\title{
IMPLEMENTASI PROGRAM BIMBINGAN PERKAWINAN DI KOTA TASIKMALAYA
}

\author{
${ }^{1}$ Dede Nurul Qomariah, ${ }^{2}$ Ekha Wahyuni, ${ }^{3}$ Lippi Fiqriya Pangestu, ${ }^{4}$ Moch Alfi Ridho, ${ }^{5}$ Restu Wijaya Dimas \\ ${ }^{1}$ Jurusan Pendidikan Islam Anak Usia Dini, STITNU Al-Farabi Pangandaran \\ 2,3,4,5 Jurusan Pendidikan Masyarakat, Fakultas Keguruan dan Ilmu Pendidikan, Universitas Siliwangi \\ dedenurulqomariah2@gmail.com,
}

\begin{abstract}
ABSTRAK
Program bimbingan pranikah merupakan program yang bersifat bottom-up sebagai salah satu upaya yang dilakukan pemerintah dalam menekan angka perceraian di masyarakat. Tujuan artikel ini untuk mengeksplorasi implementasi program bimbingan perkawinan di Kota Tasikmalaya. Metode penelitian deskriptif dengan pendekatan kualitatif digunakan dalam penelitian ini. Teknik pengumpulan data dilakukan melalui dengan observasi, wawancara dan studi dokumentasi. Hasil penelitian menunjukan bahwa: a) program bimbingan perkawinan merupakan program bottom-up karena digulirkan dari pemerintah kemudian secara vertikal dilaksanakan di masyarakat. Digulirkannya program bimbingan perkawinan dilatarbelakangi oleh tingginya angka perceraian di Indonesia yang semakin meningkat sehingga program ini diharapkan mampu menjadi salah satu upaya preventif dalam menekan angka perceraian di Indonesia; b) Secara regulasi program bimbingan perkawinan sudah sejalan dengan perundangan yang telah ada sebelumnya. Ditambah dengan modul yang cukup memadai sebagai bekal pengetahuan peserta program. Oleh karena itu implementasi program di lapangan harus menjadi fokus pemerintah dalam menjaga komitmennya mewujudkan pembangunan keluarga sejahtera.
\end{abstract}

Kata Kunci: keluarga, perkawinan, pranikah, bimbingan perkawinan.

\begin{abstract}
The premarital guidance program is a bottom-up program as one of the efforts made by the government in suppressing the divorce rate in society. The purpose of this article is to explore the implementation of the marriage guidance program in Tasikmalaya City. Descriptive research method with a qualitative approach is used in this study. Data collection techniques were carried out through observation, interviews and documentation studies. The results of the study show that: a) the marriage guidance program is a bottom-up program because it is rolled out from the government and then vertically implemented in the community. The launching of the marriage guidance program is motivated by the increasing number of divorces in Indonesia so that this program is expected to be one of the preventive efforts in suppressing the divorce rate in Indonesia; b) The regulation of the marriage guidance program is in line with the existing legislation. Coupled with a module that is quite adequate as a provision of knowledge of program participants. Therefore, the implementation of the program in the field must be the focus of the government in maintaining its commitment to realizing the development of prosperous families.
\end{abstract}

Keywords: family, marriage, premarital, marriage guidance. 


\section{PENDAHULUAN}

Indonesia telah sejak dahulu mengatur berbagai aturan dalam pernikahan sudah di melalui undang-undang pernikahan mulai dari usia, persyaratan administrasi dan lain sebagainya. Menurut undang-undang nomor 1 tahun 1974 tentang perkawinan pada pasal 1 disebutkan bahwa perkawinan ialah ikatan lahir bathin antara seorang pria dengan wanita sebagai suami isteri dengan tujuan membentuk rumah tangga (keluarga) yang bahagia dan kekal berdasarkan ketuhanan Yang Maha Esa. Perkawinan merupakan hubungan yang diakui secara sosial antara seorang pria dan seorang wanita yang menyediakan hubungan seksual, melahirkan anak yang sah dan membangun pembagian kerja diantara pasangan (Duvall \& Miller, 1985). Berdasarkan Peraturan Pemerintah dan surat keputusan Kementerian Agama bersama Mahkamah Agung dalam Kompilasi Hukum Islam (KHI) pasal 2 disebutkan bahwa pernikahan merupakan suatu akad yang sangat kuat untuk mentaati perintah Allah dan melaksanakannya merupakan ibadah. Sedangkan menurut Paul Scholten dalam R. Soetojo Prawirohamidjo dan Asis Safioedin (1984) mendefinisikan perkawinan sebagai suatu hubungan hukum antara seorang pria dan wanita untuk hidup bersama dengan kekal yang diakui negara.

Secara yuridis pernikahan di Indonesia diatur sedemikian rupa guna mewujudkan pembangunan keluarga yang melahirkan generasi penerus yang sah dalam ikatan pernikahan. Namun seiring dengan perubahan sosial yang terjadi dan perubahan arus globalisasi menyebabkan minimnya kesiapan masyarakat menuju pernikahan. Berdasarkan data dari Pengadilan Agama Kota Tasikmalaya (2018) kasus perceraian terjadi sebanyak 4.061 kasus diawali oleh pertengkaran suami-istri sehingga menyebabkan kekerasan dalam rumah tangga dengan jumlah mencapai 135 kasus. Pertengkaran yang berujung pada kekerasan dalam rumah tangga terkait dengan rendahnya pengelolaan emosi suami-isteri. Disinilah pentingnya pembekalan pengetahuan bagi calon pasangan yang akan menikah sehingga peserta program memiliki kesiapan yang matang menuju pernikahan. Konflik dalam rumah tangga tidak dapat dihindari, namun kesiapan pasangan dalam menghadapinya merupakan suatu keharusan yang patut untuk dipersiapkan. Konflik dalam keluarga tidak akan berujung pada perceraian apabila setiap anggota keluarga menyadari peran masing-masing dalam keluarga. Peran keluarga dibentuk melalui rasa komitmen bersama dan komunikasi terbuka di antara anggota keluarga (Coyne, et.al., 2012).

Guna meminimalisir tingkat perceraian dan kekerasan dalam rumah tangga yang terjadi di masyarakat juga untuk memperkuat kesiapan calon pasangan, Kementrian Agama mengadakan program bimbingan perkawinan yang diikuti oleh calon pasangan menikah. Secara yuridis pelaksanaan bimbingan perkawinan ini sudah dijelaskan dalam KEPDIRJEN BIMAS Islam Nomor 379 Tahun 2018 Tentang Petunjuk Pelaksanaan Bimbingan Perkawinan disebutkan bahwa pranikah bagi calon pengantin yang bertujuan untuk menambah wawasan dan pengetahuan tentang manajemen keluarga yang baik, sehingga dalam berkeluarga tercipta keharmonisan dan menjadi keluarga sakinah, mawaddah warahmah. Berdasarkan data studi dokumentasi dari KUA Cihideung Kota Tasikmalaya diperoleh informasi bahwa sejak tahun 2017 tingkat perceraian terjadi sebanyak 4.147 kasus, tahun 2018 terjadinya perceraian sebanyak 4.061 kasus, dan tahun 2019 terjadi perceraian kurang lebih 2.000 kasus. Hal ini memberi gambaran bahwa telah terjadi penurunan kasus perceraian yang terjadi di Kota Tasikmalaya, namun belum diketahui pasti apakah tingkat penurunan tingkat perceraian ini disebabkan oleh efektifnya program bimbingan perkawinan yang dilaksanakan. Ini memerlukan studi lebih lanjut. 
Program bimbingan perkawinan termasuk kedalam program pendidikan (pranikah) yang bertujuan meningkatkan pengetahuan dalam mempersiapkan diri untuk berkeluarga. Sehingga program bimbingan perkawinan seharusnya termasuk program penting dalam mencegah perceraian di masyarakat. Program bimbingan perkawinan secara yudiris sangat cocok untuk dilakukan dalam rangka mengintervensi keluarga sejak dini sehingga pada akhirnya mampu menekan angka perceraian di masyarakat. Sejalan dengan penelitian sebelumnya Melissa LK (2005) melaporkan bahwa intervensi pranikah (yaitu konseling atau pendidikan) telah terbukti efektif dalam berbagai cara yang berbeda, misalnya peningkatan langsung dan jangka pendek dalam keterampilan interpersonal dan kualitas hubungan secara keseluruhan, kemungkinan menurunkan faktor risiko (misalnya keterampilan komunikasi yang buruk) untuk masalah perkawinan di kemudian hari dan meningkatkan kualitas hidup untuk pasangan dan keluarga yang tinggal bersama. Selanjutnya El-Hazmi MA (2006) melaporkan bahwa konseling pranikah juga merupakan prosedur yang paling tepat, karena secara umum dapat diterima dari sudut pandang agama dan etika serta persyaratan kesehatan dan ekonomi yang minimal. Oleh karena itu penelitian ini bertujuan untuk mengetahui bagaimana implementasi program bimbingan perkawinan sebagai upaya intervensi dini keluarga di Kota Tasikmalaya.

\section{KAJIAN TEORI}

Menurut W.S Winkel (2004) bimbingan adalah pemberian bantuan kepada seseorang atau sekelompok orang dalam membuat pilihan-pilihan secara bijaksana dalam mengadakan penyesuaian diri terhadap tuntunan hidup, bantuan itu bersifat psikologis dan tidak berupa pertolongan finansial, medis dan sebagainya. Menurut Shertzer dan Stone (2009) bimbingan sebagai suatu proses bantuan yang ditujukan kepada individu agar mengenali dirinya dan dunianya. Menurut Bimo Walgito (2004) bimbingan adalah bantuan atau pertolongan kepada individu atau kelompok dalam menghindari atau mengatasi kesulitan-kesulitan di dalam hidupnya agar setiap individu dapat mencapai kesejahteraan hidupnya.

Nikah secara terminologis diartikan sebagai akad atau perjanjian yang mengandung maksud membolehkan hubungan kelamin dengan menggunakan kata "nakaha" atau "zawwaja" (Lajnah Pentashihan Mushaf Al-Qur'an Badan Litbang Dan Diklat Kementerian Agama RI, 2014). Menurut Syubandono (1981) bimbingan pranikah adalah suatu proses pelayanan sosial berupa suatu bimbingan atau penasehatan, pertolongan yang diberikan kepada calon suami istri, sebelum melaksanakan pernikahan, agar mereka memperoleh kesejahteraan dan kebahagiaan dalam perkawinan dan kehidupan kekeluargaan. Menurut Aunur Rahim Faqih (2001) bimbingan pernikahan dan keluarga islami adalah proses pemberian bantuan terhadap individu agar menjalankan pernikahan dan kehidupan berumah tangganya bisa selaras dengan ketentuan dan petunjuk Allah Subhanahu Wata'ala sehingga bisa mencapai kebahagiaan hidup di dunia dan di akhirat. Menurut Santika (dalam Nurfauziyah, 2017) bimbingan pranikah merupakan suatu pola bimbingan yang ditunjukkan untuk membantu, memahami dan menyikapi konsep pernikahan dan hidup berkeluarga keagamaan sebagai rujukan dalam mempersiapkan pernikahan yang mereka harapkan. Menurut Muhammad Iklil \& Nur Kholis (2016) bimbingan pra nikah adalah suatu proses pendampingan kepada seseorang yang akan melangsungkan perkawinan agar dapat memaksimalkan kemampuannya sehingga dapat mengoptimalkan manfaatnya bagi dirinya, perkawinannya, hingga masyarakat. Lebih luas Satriah (2017) menyebutkan bahwa bimbingan pranikah merupakan pelatihan berbasis pengetahuan dan keterampilan yang menyediakan informasi mengenai pernikahan yang dapat 
bermanfaat untuk mempertahankan dan meningkatkan hubungan pasangan yang akan menikah serta mampu memahami konsep pernikahan dan hidup berkeluarga berdasarkan peran dan fungsinya dalam keluarga. Jalil (2019) mendefinisikan program bimbingan pranikah merupakan rancangan mengenai petunjuk dan tuntunan tentang hakikat pernikahan bagi calon pengantin yang akan membangun rumah tangga. Dalam penelitian ini program bimbingan perkawinan merupakan proses pemberian bantuan oleh pembimbing atau penyuluh kepada calon pasangan agar mereka bisa mengembangkan pengetahuan, kemampuan, dan kesiapannya untuk berkeluarga demi mewujudkan keluarga sejahtera.

\section{METODOLOGI}

Metode penelitian yang digunakan dalam penelitian ini adalah metode deskriptif dengan pendekatan kualitatif. Menurut Nazir (1998) metode deskriptif merupakan suatu metode dalam meneliti status sekelompok manusia, suatu objek suatu set kondisi suatu sistem pemikiran ataupun suatu kelas peristiwa pada masa sekarang. Sedangkan menurut Sugiyono (2005) menyatakan bahwa metode deskriptif adalah salah satu metode yang digunakan untuk menggambarkan atau menganalisis suatu hasil penelitian tetapi tidak digunakan untuk membuat kesimpulan yang lebih luas. Teknik pengumpulan data dalam penelitian ini yaitu observasi, wawancara, dan studi dokumentasi. Teknik purposive sampling dipilih dalam menentukan partisipan penelitian. Teknik purposive sampling yaitu teknik penentuan sample dengan pertimbangan tertentu (Sugiyono, 2005). Penelitian ini dilakukan pada bulan Maret 2020, berlokasi di KUA Cihideung Kota Tasikmalaya.

\section{HASIL PENELITIAN DAN PEMBAHASAN}

\section{Latarbelakang Program Bimbingan Perkawinan}

Program bimbingan perkawinan (BIMWIN) merupakan program salah satu kegiatan yang digulirkan oleh Kementerian Agama Republik Indonesia sejak ditetapkannya Peraturan DIRJEN BIMAS Islam No. DJ.II/491 Tahun 2009 tentang kursus calon pengantin kemudian aturan tersebut diperbarui dengan peraturan tentang pedoman penyelenggaraan kursus pranikah yang diatur dalam Pasal 2 Peraturan Direktur Jendral Bimbingan Masyarakat Islam No. DJ. II/542 Tahun 2013 tentang Pedoman Penyelenggaraan Kursus Pra Nikah.

Mengacu pada keputusan Menteri Agama nomor 517 tahun 2001 tentang penataan organisasi kantor urusan agama, KUA Kecamatan bertanggungjawab kepada Kepala Kantor Departemen Agama Kota yang dikoordinasi dengan Kepala Seksi Urusan Agama Islam / Bimbingan Masyarakat Islam dan Kelembagaan Agama. Oleh karenanya program BIMWIN yang dilakukan oleh KUA Cihideung Kota Tasikmalaya merupakan salah satu tugas dan fungsi KUA di masyarakat dalam rangka pengembangan kependudukan dan keluarga sakinah. Sebagai bentuk komitmennya dalam upaya pengembangan kependudukan dan keluarga sakinah KUA Kecamatan Cihideung Kota Tasikmalaya memberlakukan setiap calon pengantin yang hendak melangsungkan pernikahan diharuskan mengikuti BIMWIN yang dilaksanakan di KUA. Sehingga bisa dipastikan bahwa program bimbingan perkawinan bagi calon pengantin ini merupakan wujud nyata kesungguhan Kementerian Agama dalam memastikan pembangunan bangsa melalui keharmonisan perkawinan yang ideal. 
Program BIMWIN dilatarbelakangi oleh tingginya angka perceraian yang terjadi di Indonesia. Dalam sepuluh tahun terakhir data perceraian di Indonesia semakin meningkat setiap tahunnya termasuk di Kota Tasikmalaya. Tingginya kasus perceraian di Kota Tasikmalaya diakibatkan oleh faktor ekonomi dan ketidaksiapan pasangan dalam membina rumah tangga sehingga kurang memahami arti pernikahan yang sebenarnya. Pernikahan muda adalah pernikahan yang dilakukan oleh pasangan ataupun salah satu pasangannya masih dikategorikan remaja yang berusia di bawah 19 tahun (WHO, 2006). Pernikahan diusia yang masih muda tentu merupakan kondisi yang rentan dan masih labil. Banyak studi sebelumnya melaporkan hal ini (Pau, Joseph, dan Ijeoma, 2013; Tsania, 2014; Dabone dan Tawiah, 2014; Shabbir, Nisar, dan Fatima, 2015; Fatma Putri Sekaring Tyas, et.al 2017). Kasus perceraian yang terus meningkat mengindikasikan pasangan kurang memiliki kesiapan dan kematangan dalam membina pernikahan sehingga tidak tercapai kepuasan pernikahan. Oleh karena itu program BIMWIN cocok digunakan sebagai alternatif preventif dalam mempersiapkan calon pasangan menikah agar memiliki bekal pengetahuan yang cukup tentang pernikahan serta sebagai penguatan kesiapan diri calon pasangan untuk membina keluarga sejahtera.

Untuk menanggulangi hal ini, pemerintah melalui Kementerian Agama menggulirkan program bimbingan perkawinan bagi pasangan yang akan menikah dengan harapan setelah mengikuti program ini pasangan yang akan menikah memiliki pengetahuan, keterampilan, dan kesiapan yang cukup secara fisik dan mental untuk membentuk keluarga sakinah mawaddah, warahmah. Keputusan Direktorat Jenderal Bimbingan masyarakat Islam Nomor 379 Tahun 2018 Tentang Petunjuk Pelaksanaan Bimbingan Perkawinan Pranikah Bagi Calon Pengantin, disebutkan bahwa bimbingan perkawinan pranikah bagi calon pengantin diprioritaskan untuk calon pengantin yang telah mendaftar di KUA Kecamatan. Ini dimaksudkan agar pasangan yang akan menikah memahami tujuan menikah dan mengetahui hak serta kewajibannya sebagai suami-istri kelak.

Secara yuridis program BIMWIN di Jawa Barat sangat strategis untuk dilakukan, karena program ini merupakan implementasi dari berbagai undang-undang. Mulai dari hanya undangundang perkawinan, undang-undang tentang perkembangan kependudukan dan pembangunan keluarga sejahtera, hingga PERDA JABAR tentang penyelenggaraan pembangunan ketahanan keluarga. Pelaksanaan program BIMWIN dapat dikatakan sebagai pembinaan gerakan keluarga sakinah regulasinya jelas, tinggal bagaimana implementasinya dapat dilaksanakan secara merata di seluruh Indonesia. Pada pasal 9 Keputusan Direktur Jenderal Bimas Islam dan Penyelenggaraan Haji Nomor D/71/1999 Tentang Petunjuk Pelaksanaan Pembinaan Gerakan Keluarga Sakinah disebutkan bahwa kegiatan keluarga sakinah dilaksanakan oleh masyarakat dan Pemerintah, masyarakat sebagai pemeran utama dan Pemerintah sebagai fasilitator dan dinamisator. Disinilah program BIMWIN dikatakan program bottom-up atau program yang berasal dari pemerintah yang dilakukan di masyarakat.

Program BIMWIN merupakan program edukasi bagi masyarakat atau calon pasangan menikah dengan tujuan mendukung pembangunan keluarga berkualitas. Keluarga berkualitas merupakan keluarga yang dibentuk berdasarkan perkawinan yang sah dan bercirikan sejahtera, sehat, maju, mandiri, memiliki jumlah anak yang ideal, berwawasan ke depan, bertanggung jawab, harmonis dan bertakwa kepada Tuhan Yang Maha Esa (Undang-Undang Nomor 52 Tahun 2009 Tentang Perkembangan Kependudukan dan Pembangunan Keluarga). Karena itu, program BIMWIN yang berjalan harus menjadi fokus Kementrian Agama dalam menjaga 
konsistensinya dalam mewujudkan pembangunan keluarga Indonesia sejahtera. Program bimbingan pranikah tidak hanya dilakukan di Indonesia tetapi juga dilaksanakan di beberapa negara lainnya seperti Saudi Arabia dan Jerman. Temuan penelitian terdahulu melaporkan bahwa screening pra-nikah dipandang baik dari sudut agama dan kesehatan (El-Hazmi MA., 2006). Selain itu screening pra-nikah penting dilakukan untuk menjaga kualitas hidup dan kesehatan di keluarga (Ibrahim, N. K. R, 2011). Selain itu sikap positif dari mayoritas penduduk Arab Saudi muncul untuk mendukung program screening pra-nikah, sehingga sehingga program ini berlaku untuk seluruh masayarakat terutama pasangan yang akan menikah (Al Suliman et al, 2008). Lebih jauh Ibrahim (2011) melaporkan hasil penelitiannya bahwa program screening pra-nikah berhasil meningkatkan pengetahuan masyarakat secara umum dan menyadari bahwa kualitas hidup keluarga itu hal yang penting. Studi lain yang dilakukan di Jerman program pendidikan pra-nikah bertujuan untuk mengurangi gejala konflik dalam suatu hubungan termasuk di kalangan pemuda, pasangan pra-nikah, pasangan yang sudah menikah, dan pasangan yang sudah memiliki anak (Ann-Katrin Job, Donald H. Baucom \& Kurt Hahlweg, 2016). Temuan lainnya menemukan bahwa program CRE secara efektif membantu individu atau pasangan dalam mempertahankan hubungan yang sehat dengan pasangan dan anak-anak mereka, memperkecil kemungkinan marabahaya dalam hubungan hingga memperkecil perceraian (Ann-Katrin Job, Donald H. Baucom \& Kurt Hahlweg 2016; Hawkins, Amato, \& Kinghorn, 2013).

\section{Penyelenggaraan Program Bimbingan Perkawinan}

Program untuk mendukung pasangan dalam mengembangkan dan mempertahankan hubungan yang sehat mengalami peningkatan minat dalam beberapa dekade terakhir. dalam penelitian ini ditemukan pula bahwa program bimbingan perkawinan pada dasarnya merupakan salah satu program yang mendukung pasangan dalam memasuki gerbang pernikahan. Pelaksanaan program BIMWIN dilakukan secara tatap muka selama 16 jam pelajaran (JP) sesuai dengan modul yang diterbitkan oleh Kementerian Agama. Pemberian materi dilakukan oleh dua orang atau lebih fasilitator atau penyuluh dari KUA yang telah mengikuti dan memiliki sertifikat fasilitator BIMWIN pranikah bagi calon pengantin yang diselenggarakan oleh Kementerian Agama atau lembaga lain yang telah mendapatkan izin Kementerian Agama. Bekerjasama dengan narasumber dari Puskesmas setempat untuk beberapa materi yang terkait dengan kesehatan reproduksi. Metode pembelajaran yang diterapkan adalah ceramah dan tanya jawab. Materi BIMWIN yang dilaksanakan adalah sebagai berikut:
a. Paparan kebijakan bimbingan perkawinan (2 jam pelajaran)
b. Perkenalan, pengutaraan harapan, dan kontak belajar (1 jam pelajaran)
c. Mempersiapkan keluarga sakinah (2 jam pelajaran)
d. Membangun hubungan dalam keluarga (3 jam pelajaran)
e. Memenuhi kebutuhan keluarga (2 jam pelajaran)
f. Menjaga kesehatan reproduksi (2 jam pelajaran)
g. Mempersiapkan generasi berkualitas (2 jam pelajaran)
h. Refleksi, evaluasi, dan post tes ( 2 jam pelajaran). 
Calon pasangan yang menjadi peserta kegiatan program BIMWIN minimal berjumlah 25 pasang atau berjumlah 50 orang. Sebagian besar peserta program BIMWIN merespon positif pelaksanaan program ini. Mereka merasa mendapatkan banyak materi yang bermanfaat dari narasumber tentang hakikat pernikahan, keluarga, hingga terkait kesehatan reproduksi. Keaktifan peserta program BIMWIN dalam mengikuti pembelajaran tatap muka sejalan dengan hasil observasi yang dilakukan oleh kami bahwa peserta cukup antusias menyimak materi yang diberikan selama pemberian materi berlangsung. Pemberian materi selama 16 jam pelajaran dalam program BIMWIN, diharapkan mampu meningkatkan pengetahuan calon pasangan menikah khususnya mengenai perannya dalam keluarga. Faktor pendidikan juga dapat berhubungan dengan pengetahuan orang tua dalam melaksanakan tugas perkembangan keluarga (Fatma Putri Sekaring Tyas, et.al 2017). Tidak hanya itu program pendidikan pranikah secara nyata meningkatkan pengetahuan peserta. Informasi yang diberikan selama program pendidikan dapat membantu membuat siswa lebih sadar akan bahaya dan lebih selektif terhadap pasangan masa depan mereka. Mereka akan menyebarkan pengetahuan dan ide yang telah dikoreksi kepada teman, keluarga dan komunitas mereka (Ibrahim, N. K. R., 2011).

Beberapa hambatan ditemukan dalam pelaksanaan program BIMWIN yang dilaksanakan di KUA Kecamatan Cihideung yakni: a) waktu pemberian materi yang dilakukan selama satu hari (full day) dinilai kurang efektif oleh peserta program karena mereka merasa pemberian materi cenderung dipaksakan dan mereka juga merasa kehilangan konsentrasi saat menyimak banyak materi dalam satu hari; b) ketidakhadiran peserta program saat salah satu pasangan berada di luar kota sehingga tidak bisa mengikuti program BIMWIN secara langsung. Namun hal ini dapat tanggulangi dengan alternatif bimbingan mandiri. Bimbingan mandiri dilakukan jika salah satu calon pengantin tidak dapat mengikuti bimbingan tatap secara langsung, dapat mengikuti program BIMWIN setelah melaksanakan pernikahan; c) metode pembelajaran yang seharusnya menggunakan pendekatan andragogi, masih tampak lebih ke pendekatan pedagogi, sehingga dialog interaktif kurang terjalin; serta d) keterbatasan fasilitas media pembelajaran yang harus digunakan untuk mendukung pembelajaran tatap muka.

\section{KESIMPULAN}

Temuan saat ini menemukan bahwa program bimbingan perkawinan penting untuk dilakukan dalam upaya membekali calon pasangan dalam berkeluarga. Program bimbingan perkawinan merupakan program bottom-up karena digulirkan dari pemerintah kemudian secara vertikal dilaksanakan di masyarakat. Digulirkannya program bimbingan perkawinan dilatarbelakangi oleh tingginya angka perceraian di Indonesia yang semakin meningkat sehingga program tersebut diharapkan mampu menjadi salah satu upaya preventif dalam menekan angka perceraian di Indonesia. Secara regulasi program bimbingan perkawinan sudah sejalan dengan perundangan yang telah ada sebelumnya. Ditambah dengan modul yang cukup memadai sebagai bekal pengetahuan peserta program. Oleh karena itu implementasi program di lapangan harus menjadi fokus pemerintah dalam menjaga komitmennya mewujudkan pembangunan keluarga sejahtera. Adapun rekomendasi dalam penelitian ini: 
1. Program bimbingan pranikah yang dilaksanakan layak untuk dipertahankan, ditingkatkan kualitasnya (narasumber dan fasilitas media pembelajaran), hingga pendanaan yang memadai untuk operasional program.

2. Pengelola program perlu menyusun ulang pelaksanaan program bimwin secara berkala, agar materi yang disampaikan kepada peserta program dapat tersampaikan secara menyeluruh dan peserta memperoleh manfaat yang lebih banyak.

3. Program bimbingan pranikah secara regulasi sudah sangat sejalan dengan perundangundangan yang ada terutama dalam undang-undang yang fokus pada pembangunan keluarga, hal ini terkait dengan upaya pemerintah dalam menyusun strategi kebijakan yang mendukung kelancaran program ini dilapangan.

\section{DAFTAR PUSTAKA}

Al Sulaiman A, Suliman A, Al Mishari M, Al Sawadi A, Owaidah TM. Knowledge and attitude toward the hemoglobinopathies premarital screening program in Saudi Arabia: populationbased survey. Hemoglobin 2008; 32(6):531-8

Ann-Katrin Job, Donald H. Baucom \& Kurt Hahlweg (2016): Who Benefits from Couple Relationship Education? Findings from the Largest German CRE Study, Journal of Couple \& Relationship Therapy, DOI: 10.1080/15332691.2016.1178616

Aunur Rahim Faqih, (2001). Bimbingan dan Konseling dalam Islam, UII Pers: Yogyakarta.

Bimo, Walgito. (2004). Pengantar Psikologi Umum. Jakarta: Penerbit Andi.

Coyne, et.al., (2012). Exploration of the family's role and strengths after a young woman is diagnosed with breast cancer: Views of women and their families. European Journal of Oncology Nursing 16 (2012) 124e130.

Dabone, \& Tawiah K. (2014). Effects of age on marital satisfaction of married people in Sunyai Municipality. International Journal of research In Social Sciences, 3(8),48- 57

Duvall dan Miller dalam Anggia Kargeti Evanurul Marretih. (2016). Psikologi Perkawinan dan Keluarga, Al-Mujtahadah Pers: Pekan Baru.

El-Hazmi MA. (2006). Pre-marital examination as a method of prevention from blood genetic disorders. Community views. Saudi Med J; 27 (9): 1291—5.

Fatma Putri Sekaring Tyas, et.al. (2017). Tugas Perkembangan Keluarga dan Kepuasan Pernikahan Pada Pasangan Menikah Usia Muda. Jur. Ilm. Kel. \& Kons., Januari 2017, p : 83-94 Vol. 10, No.2 DOI: http://dx.doi.org/10.24156/jikk.2017.10.2.83

Hawkins, A. J., Amato, P. R., \& Kinghorn, A. (2013). Are government-supported healthy marriage initiative affecting family demographics? A state-level analysis. Family Relations, 62, 501- 513. 
Ibrahim, N. K. R. (2011). An educational program about premarital screening for unmarried female students in King Abdul-Aziz University, Jeddah. Elsevier: Journal of Infection and Public Health 4, 30-4

Jalil, A. (2019). Implementasi Program Bimbingan Perkawinan Pranikah Bagi Calon Pengantin di KUA Kecamatan Cilandak Kota Jakarta Selatan. Andragogi: Jurnal Diklat Teknis Pendidikan dan Keagamaan Vol. 7, No. 2, Desember.

KEPDIRJEN BIMAS Islam Nomor 379 Tahun 2018 Tentang Petunjuk Pelaksanaan Bimbingan Perkawinan.

Keputusan Direktur Jenderal Bimas Islam dan Penyelenggaraan Haji Nomor D/71/1999 Tentang Petunjuk Pelaksanaan Pembinaan Gerakan Keluarga Sakinah.

Melissa LK. (2005). At-risk Individuals' Awareness, Motivation, Roadblocks to Participation in Premarital Interventions, and Behaviors Following Completion of The Relationship Evaluation. Thesis (Master of Science). Marriage and Family Therapy Program. Brigham Young University.

Muhammad Iklil \& Nur Kholis. (2016). Implementasi Bimbingan Kursus Pra Nikah Di Kabupaten Jepara. ISTI ${ }^{\mathrm{ee}} \mathrm{DAL}$; Jurnal Studi Hukum Islam, Vol. 3 No. 2 Juli-Desember 2016. ISSN: 2356-0150

Nazir, M. (1998). Metode Penelitian. Ghaila Indonesia: Jakarta.

Nurfauziyah, A. (2017). Bimbingan Pranikah bagi Calon Pengantin dalam Mewujudkan Keluarga Sakinah. Irsyad : Jurnal Bimbingan, Penyuluhan, Konseling, dan Psikoterapi Islam Volume 5, Nomor 4, 2017, 449-468

Paul N, Joseph U. O, \& Ijeoma O. C. (2013). Education an antidote against early marriage for the girl-child. Journal of Educational and Social Research, 3(5),73-78.

Paul Scholten dalam R. Soetojo Prawirohamidjo dan Asis Safioedin tahun 1984. Tersedia dalam https://raypratama.blogspot.com/2012/02/pengertian-perkawinan.html. [diakses pada tanggal 6 Mei 2020].

Satriah Lilis. (2017). Bimbingan Konseling Keluarga. Bandung: CV. Mimbar Pustaka.

Shabbir S., Nisar S. R., \& Fatima S. (2015). Depression, anxiety, stress, and life satisfaction among early and late marriage females. European Journal of Business and Social Sciences, 4(8),128- 131.

Shertzer dan Stone dalam Syamsul Yusuf, A Juntika Nurihsan, (2009). Landasan dan Bimbingan Konseling. Bandung: PT Remaja Rosdakarya.

Sugiyono. (2005). Metode Penelitian Administrasi. Alfabeta: Bandung.

Syubandono. (1981). Pokok-pokok Pengertian dan Metode Penasehatan Perkawinan “Marriage Conseling” dalam Nasihun, Amin (2018). Pelaksanaan Bimbingan Pranikah 
di Kantor Urusan Agama Kecamatan Ilir Timur Palembang. Skripsi. Fakultas Ilmu Tarbiyah UIN Raden Fatah. Diterbitkan.

Tsania N. (2014). Karakteristik Keluarga, Kesiapan Menikah Istri dan Perkembangan Anak Usia 3-5 Tahun (Tesis). Institut Pertanian Bogor, Bogor, Indonesia.

Undang-Undang Nomor 1 Tahun 1974 Tentang Perkawinan.

Undang-Undang Nomor 52 Tahun 2009 Tentang Perkembangan Kependudukan dan Pembangunan Keluarga.

World Health Organization [WHO]. (2006). Married Adolencents: No Place of Safety. Geneva, Switzerland $(\mathrm{CH})$ : WHO Press.

W.S. Winkel, (2009). Bimbingan dan Konseling di Sekolah. Gramedia: Jakarta.

. (2014). Lajnah Pentashihan Mushaf Al-Qur'an Badan Litbang dan Diklat Kementerian Agama RI. 